\title{
Paul V. Stock, Michael Carolan \& Christopher Rosin (eds.), Food Utopias: Reimagining citizenship, ethics and community, New York: Routledge, 2015.
}

\author{
Recensão de Miguel Ramalhete Gomes \\ Universidade do Porto / Instituto Politécnico do Porto
}

A colecção de ensaios Food Utopias: Reimagining citizenship, ethics and community, editada por Paul V. Stock, Michael Carolan e Christopher Rosin (2015), propõe uma abordagem original, informada e convincente ao urgente problema da alimentação na contemporaneidade, abordagem esta que consiste em mobilizar o conceito de utopia para reconfigurar o nosso entendimento da questão da alimentação. Ao longo de dois prefácios e doze capítulos, os participantes deste volume, oriundos de áreas como a sociologia, a geografia, o direito, a antropologia, os estudos ambientais e os estudos utópicos, identificam problemas, propõem soluções, e apresentam conceitos, movimentos e práticas enquanto utopias alimentares imaginadas no futuro ou colocadas já em prática, com níveis variados de sucesso, a nível local ou global. 0 alcance destes capítulos é também saudavelmente internacional, referindo-se a processos iniciados na Argentina, Itália, Suíça e nos EUA. 0 resultado final é claramente positivo, encorajando leitores a também eles contribuírem para a apreciável diversidade de posições em jogo neste campo. Este volume apresenta ainda uma coesão notável em termos do panorama de volumes colectivos, já que combina uma muito recomendável abertura conceptual e prática com uma série de perguntas de 
investigação concretas, enunciadas tanto na introdução geral como no capítulo teórico de Lyman Tower Sargent, e abordadas ao longo dos vários capítulos.

Para além de colocarem as actuais utopias alimentares no contexto de esforços teóricos e práticos ao longo da história, os dois prefácios, da autoria de Frederick Kirschenmann e de Wes Jackson, traçam algumas questões preliminares, declarando uma predisposição para revitalizar e reclamar o conceito de utopia como contraponto à actual distopia alimentar da agricultura industrial dominada por uma ideologia de progresso técnico-científico. Como os dois prefácios notam, esta concepção de progresso tende a ignorar limites e a desinteressar-se de proteger e manter sustentável o ecossistema, confiando antes na ideologia do progresso e do crescimento infinito, baseados num método extractivo e quantitativo. Por oposição a este estado de coisas, os autores procuram estabelecer uma relação positiva com a ideia de utopia, manifestando-se na maioria destes ensaios a consciência sóbria de que a utopia deve ser praticada de forma diferente da clássica, por exemplo, de maneira local e gradual. A utopia cumpre assim, no âmbito deste volume, várias funções. Começando como crítica do sistema actual, pode depois tornar-se: um plano detalhado na direcção do qual se trabalha; um plano entendido como nunca atingível e modificável à medida que se avança; um plano que é adoptado à partida como o próprio percurso, numa política prefigurativa; ou ainda um processo sem finalidade clara à vista. Não faltando embora objectivos e discussões sobre como as atingir, estas utopias apresentam-se como não prescritivas, passíveis de serem infinitamente repensáveis e combinadas entre si.

Na introdução, os editores, Paul V. Stock, Michael Carolan e Christopher Rosin, propõem que se conte histórias novas sobre a alimentação, histórias críticas e de esperança, recusando-se, por outro lado, narrativas únicas e universais ou soluções milagrosas, como a actual narrativa alimentar dominada pela ideologia da produção e mercantilização (4). Insiste-se antes na diversidade e multiplicidade de histórias, assim como na importância de estas poderem ser combinadas. Lembrando a frase de Claude Levi-Strauss, segundo o qual é bom pensar com a comida, estas histórias alimentares são propostas como instrumento de mediação (5), através do qual as utopias possam tornar-se realidade. 
Nesse sentido, os editores propõem uma "trialéctica" das utopias alimentares entendidas como instrumento, trialéctica esta composta de crítica, experimentação e processo: "Food utopias help us critique (and decenter) conventional narratives, document experiments whereby food is being done differently, and emphasize that the practice of food or doing food differently is an often messy and always indeterminate process" (6). Os editores concordam que a crítica é idealmente produtiva, conduzindo ao conceito de Paul Ricoeur da utopia como exploração do possível, visando abrir um espaço no qual pensar alternativas. 0 segundo elemento da trialéctica, a experimentação, visa introduzir uma série de posicionamentos na prática, nomeadamente "relational geography (...), enactive scholarship (...), prefigurative politics (...), and performative and embodied theorizing" (8). Determinante é a importância dada a um estado de "not-yetness", em que as experiências não precisam de ter sucesso para poderem ser visões importantes do possível: "A "won" utopian vision implies something we want no part of - an end of dialogue, a clear end game, in a word, death. It's this emphasis on process - what enlivens life - that rounds out our food utopias framework" (10). Esse entendimento do valor da experimentação conduz naturalmente ao terceiro elemento da trialéctica, a ideia de processo, segundo a qual as utopias alimentares querem ser uma forma de criar diálogo e de produzir diferença (10). Contudo, o raciocínio dos editores pode por vezes expô-los à acusação de que se fetichiza aqui a ideia de processo, com a consequência de esta elevação do processo a conceito-chave poder conduzir a uma satisfação um pouco auto-indulgente dos participantes para com as suas boas intenções, antes mesmo que estas produzam resultados necessários e urgentes. 0 ensaio de Lyman Tower Sargent que se segue à introdução pode ser considerado o texto principal do volume (do ponto de vista dos estudos utópicos) e cumpre, pelo menos, dois propósitos: em primeiro lugar, considera a questão da alimentação no corpus da literatura utópica, prática utópica, e teoria social utópica, aquilo a que Sargent chama as "três faces da utopia"; em segundo lugar, Sargent coloca uma série de perguntas de investigação de cariz materialista, que se revelam essenciais na abordagem tanto a utopias literárias como a projectos utópicos no papel e em comunidades intencionais: 
But once one asks what people eat, questions arise about how the food is produced, how it is prepared and who prepares it, how it is served and who serves it, who cleans up after the meal, and what happens to the leftovers. And these questions clearly imply such issues as the nature of families and communities, gender relations, rural/urban relations, the economics and mechanics of production, distribution, and consumption, and sanitation, and these issues also clearly relate to the political system and how decisions about these questions are made. (14)

Por oposição a um entendimento analítico em que a alimentação é abordada de forma isolada, pretende-se assim entendê-la como parte de uma rede de relações sociais: ao nível da teoria social, as questões alimentares produzem ramificações na luta contra a opressão e a desigualdade entre homens e mulheres, entre povos, raças, classes e gerações (27). Ao nível das comunidades intencionais, Sargent concentra-se em certas dificuldades: por um lado, o facto de muitos não saberem o que fazer com a comida ou como a cultivar, em consequência da propensão classista para entender a agricultura como um trabalho sem necessidade de qualificações ou especialização. Interessantemente, vários dos problemas apontados revelam o nível de alienação dos indivíduos envolvidos em relação à sua alimentação e o grau no qual certas práticas que se pretendem recuperar nestas comunidades foram esquecidas na era da agricultura industrial.

Os restantes capítulos do volume apontam vários problemas concretos, propondo soluções muitas vezes encapsuladas em movimentos já existentes. Uma narrativa comum a vários dos capítulos começa por explicar um "erro" ocorrido há dez mil anos na invenção da agricultura, com a opção por culturas anuais em vez de perenes, o que teria conduzido a todo um paradigma cultural sobre a relação entre ser humano e natureza, em que esta teria de ser dominada e submetida à vontade de quem a pretende cultivar, domando-se a terra para produzir o resultado desejado. A agricultura industrial e a revolução verde que dependem deste entendimento extractivo e explorador produzem no nosso tempo, como consequências da necessidade de alimentar sete mil milhões de pessoas, a degradação da terra, a emissão de gases de estufa, o recurso a pesticidas e outros químicos, a dependência de combustíveis fósseis, a estandardização e destruição da biodiversidade e mesmo a alienação de se esquecer que se esqueceu uma certa relação pré-industrial com os produtos 
da terra. A concentração nos fins a atingir conduz à busca por aquilo a que se tem chamado "technological fix", isto é soluções milagrosas que, pensadas a partir de dentro do mesmo sistema que produz os problemas, apenas os resolvem temporariamente, podendo exacerba-los no futuro, em vez de repensarem o sistema de raiz.

Os autores dos capítulos deste volume propõem assim uma série de conceitos mais ou menos radicais na forma como pretendem repensar ou reformar um sistema alimentar hegemónico. Defendendo-se a justiça alimentar e a soberania alimentar, os autores destes capítulos apresentam movimentos que corporizam e praticam estas ideias, tais como o movimento de La Via Campesina (Nave Wald) e o movimento da Slow Food (Cinzia Piatti), explicando-se como se tem promovido a comida local, a comida orgânica e culturas perenes (John Head), e como se tem usado formas de certificação e rotulagem para, por exemplo, promover o comércio justo e uma maior proximidade entre produtor e consumidor (Joshua Lockyer), proximidade esta que também tem sido obtida por via de mercados de lavradores e hortas urbanas (Isidor Walliman). Para além destes capítulos de ordem mais descritiva, o volume inclui ainda um capítulo, da autoria de Hugh Campbell, em que se delineia uma política positiva da alimentação para o futuro, e um capítulo particularmente estimulante de Michael Carolan em que, a propósito de desertos alimentares ("food deserts") e das falsas escolhas providenciadas por gigantes alimentares, Carolan discute a alienação, resultante de já se ter nascido no contexto da indústria agro-alimentar, de não se saber sequer que se esqueceu como lidar com certos alimentos.

De forma talvez menos positiva, o livro revela algumas ambivalências em relação à questão do mercado e da tecnologia. Por um lado, tanto Frederick Kirschenmann como Wes Jackson, nos respectivos prefácios, entendem a resolução do problema alimentar dentro de um contexto capitalista, o primeiro referindo-se ao nosso capital ecológico (xiv) e o segundo quantificando o conhecimento monetariamente ("billions of dollars worth of knowledge", xviii). A questão do valor tende assim a ser colocada como valor de mercado, o que, poderse-ia argumentar, apenas conserva o sistema que produz a maioria dos problemas para os quais se busca solução neste volume. Por analogia com o "technological fix", poderíamos assim falar de um "economic fix". As posições individuais dos autores acabam, na sua 
variedade (do anarquismo e do comunismo cristão à aceitação de variadíssimos níveis de comercialização dos produtos em causa), por ficar aquém de uma crítica mais sistemática à base económica destes problemas, embora críticas válidas sejam frequentemente feitas ao actual sistema económico, começando pela ideia de se patentear sementes e de se ser proprietário do material genético contido nelas.

Esta relação ambivalente com o capitalismo acaba por obscurecer outras relações que são objecto de confusão em alguns dos capítulos individuais, mais especialmente a relação com a tecnologia. Num capítulo sobre utopismo tecnológico, Paul V. Stock ataca uma tecnologia que diz não estar ao serviço das pessoas, sendo antes um fim em si mesma, ou seja autotélica. Contudo, imagina-se mal uma tecnologia que beneficie apenas a debulhadora ou a embalagem, mas não quem as fabrica, e esta contaminação do capítulo e de uma ou outra parte do livro por um ocasional humanismo ludita ofusca o facto de a tecnologia beneficiar sempre alguém, apesar de esse alguém poder frequentemente não ser a população em geral: quem beneficia costuma ser quem faz dinheiro a partir da tecnologia. Há portanto uma relação económica subjacente que é erroneamente traduzida como uma relação tecnológica. Exemplo disso é o capítulo de Grant Shoffstall and Zsuzsa Gille sobre a nano-tecnologia aplicada à alimentação, seu desperdício e embalamento, cuja conclusão é de que a nano-tecnologia apenas conserva o sistema que produziu o problema em primeiro lugar, podendo mesmo exacerbar-lhe os problemas, novamente num "technological fix". Sendo embora convincentemente argumentado, o capítulo alimenta um discurso no qual a tecnologia sai talvez demasiadas vezes denegrida, agravado aqui por não haver um capítulo que ofereça um contraponto afirmativo. Embora no geral o volume revele posições mais equilibradas, resulta por vezes desta linha de pensamento um certo pastoralismo e romantização da relação com a terra pautados por aquilo a que Theodor Adorno chamou “jargão da autenticidade”. E, se há várias críticas correctamente apontadas à relação com a tecnologia - nomeadamente a tendência da tecnociência para se estabelecer como ideologia totalizante, a tudo aplicável e explorando todo o mundo como seu objecto ou instrumento -, assim como a recuperação de propostas estimulantes, tal como passar a entender os instrumentos e a instrumentalidade enquanto processo, e não como domínio, nota-se 
contudo a falta de qualquer referência ao conceito de "razão instrumental" de Adorno e de Max Horkheimer e sua análise no contexto da dialéctica do Iluminismo. Apesar do arcaboiço teórico da maioria dos capítulos, o qual é, aliás, consideravelmente especializado e apropriado aos argumentos e materiais em causa, esta ausência é particularmente infeliz, pois teria permitido articular de forma mais sólida o curto-circuito que traduz como autotelia tecnológica e consequente pastoralismo o que é uma relação de base económica, de exploração da terra em continuidade com a exploração do trabalho humano.

Contudo, o capítulo 12 do volume, da autoria dos seus editores, termina com um apelo irresistível aos leitores: "We share this volume as an invitation rather than a declaration. Now it's your turn" (224). As utopias alimentares propostas neste volume são de facto objecto de considerável reflexão teórica e prática e oferecem-se à crítica e à experimentação: os argumentos utilizados e situações descritas são de inegável sofisticação e normalmente fazem jus a configurações sociais e culturais complexas. Finalmente, esta combinação de estudos sobre a alimentação com os estudos utópicos é, para já, única no panorama académico, revelando-se um objecto verdadeiramente interdisciplinar. Este volume será por isso incontornável para qualquer leitor interessado em pensamento utópico aplicado a questões alimentares, providenciando uma sólida base teórica e uma série de casos práticos ilustrativos de grande utilidade para a elaboração de trabalhos futuros - assim como para inspirar mudanças reais. 